\title{
Improvement for Better Impacts of the Market Information System or MIS in Developing Countries
}

\author{
Priscia Berthiot Rakotomalala, Jianmin Cao \\ College of Economics and Management, Jilin Agricultural University, Changchun, China \\ Email: priscia.rakotomalala@gmail.com,1379168043@qq.com
}

How to cite this paper: Rakotomalala, P.B. and Cao, J.M. (2019) Improvement for Better Impacts of the Market Information System or MIS in Developing Countries. Open Journal of Social Sciences, 7, 180-187. https://doi.org/10.4236/jss.2019.75014

Received: February 27, 2019

Accepted: May 20, 2019

Published: May 23, 2019

Copyright (อ 2019 by author(s) and Scientific Research Publishing Inc. This work is licensed under the Creative Commons Attribution International License (CC BY 4.0).

http://creativecommons.org/licenses/by/4.0/

\begin{abstract}
The agriculture sector is one of the economic pillars in a developing country. For the better governance of the sector, Market Information System (MIS) was promoted in 1980 in developing countries after the liberalization of the market and the withdrawal of Para-public from the agricultural sector. From the perspective of economic theory, the emergence of an MIS in an economy is supposed to reduce information search costs and influence the behaviour of economic agents such as producers, traders and consumers. So these agents should have access to this information to guide their decisions.
\end{abstract}

\section{Keywords}

MIS or Market Information System, Impacts, Information

\section{Introduction}

Market Information System (MIS) is a tool that collects and disseminates information to market players [1]. For a definition, the Market Information System (MIS) is on one hand a system which improves the marketing of agricultural products, and on the other hand reinforces the relevance of agricultural, food and commercial policies by better taking into account the situation and the dynamics markets [2]. For the better market transparency, their traditional operation is to collect regularly on the markets of collection, wholesale or retail information on the prices of agricultural products, possibly on the quantities marketed, and to diffuse this information with the public (States) and especially private actors in producers, traders and consumers. Presented in the majority of the countries of sub-Saharan Africa since 1980 as powerful tools to accompany these liberalization policies, they aimed in particular at solving the failures of agricul- 
tural markets related to information, characterized as incomplete and asymmetrical between the different actors (producers and traders in particular) [3]. I wrote this article because I am a student from a developing country, which is Madagascar an Island in the African continent. The MIS was introduced in Madagascar in the 2000s and is helping so far the agricultural sector of my country, such is the [4] OdR (Observatoire du Riz) or Rice Observatory which run the rice MIS in all the districts of Madagascar and [5] SIEL (Service d'Information Économique des Légumes). It is interested in the five vegetables of major economic importance in Madagascar: tomatoes, potatoes, carrots, onions and green beans. Thereof, the reason of my thesis title "The impact of market information system on Madagascar rice production", is to inform about the changes that the MIS has brought. However, my researches have tended me more to get through a conclusion that despite the considerable evolution of the MIS since the two decades, and despite its wealth as a tool of innovation, it remains confronted with many challenges need for a better improvement. So this article is going to expose the seven impacts in which the MIS still need a breakthrough.

\section{First Impact: The Unquestionable and Questionable Impact on the Development of Policies}

In a context marked by instability increased agricultural markets and the recurrence of food crises, especially in the Sahel and in the Horn of Africa, this function of the MIS appears to be paramount. Making decision-makers available information on the state and dynamic market is nature to allow an improvement in the relevance of public policies and their evaluation. To evaluate this kind of impact, one would have to be in able to observe policies that would have been implemented the absence of MIS in order to compare their policies implemented in presence of this one. It is extremely difficult to answer these questions quantitatively. MIS have they significantly influenced the public policies by allowing better consideration of realities of the markets. Do they have even led to an improvement in the well-being of the populations of development? On the other hand, it is impossible to know the policies that would have been implemented if the decision makers had less information. Simulating the impact of a hypothetical policy may be possible (with margins sometimes very important) via modeling. Even if this type of platform has a purely advisory role, they obviously contribute to the elaboration of shared diagnostics of the situation and policy options possible at the national level or local. Nevertheless, the information collected by the MIS holds an important place in the spheres of public decision. As in the case of Madagascar, the MIS data on the situation of the rice market were used to feed a platform for consultation meeting representatives of the private operators and different ministries. An impact of mobile telephony (via SMS) on the efficiency of markets theoretically was proven, when agents are perfectly informed about prices market, they are able to exploit all arbitration opportunities over time, in space and between marketable products which leads to perfect in- 
tegration market and stabilization of price. This is also the case for activation emergency help: some MIS provide information to the systems early warning which provides indicators allowing trigger public support in case of crisis [1]. In some cases, MIS play an indispensable role in construction indicators used to trigger public interventions. It's the case for example policies of price stabilization [6]. However, these works do not show to what extent this better integration of the markets would be related to the emergence of MIS, the rise of mobile telephony (concomitant with that of SIM2G) or to other aspects of the improvement marketing conditions like the liberalization of markets agricultural products (concomitant to development SIM1G), the improvement infrastructure or development market institutions. A great deal of empirical work is devoted to the analysis of the spatial integration of markets in developing countries [7]. Some works highlight that the gap between prices on markets distant from each other has diminished in time.

\section{Second Impact: Strengthen the Impact of MIS on Public Policies}

It should be noted that almost all MIS now tend to focus mainly on private operators (and the objective of market transparency): the MIS from the first generation did not give up the objective of informing public policies but they have developed very few innovations in this domain; as for new MIS, they usually do not take account for this objective. We can find this regrettable evolution, quality information essential to policy development although it is difficult to isolate and measure its impact. But it is true that producing such analyzes would assume that the MIS have strong analytical skills or collaborate with teaching and research. If MIS produced business analyzes and notes analyzing the effects of different policy options, they would probably contribute effectively to enlighten decision makers.

In this regards, the most promising forms are those where the MIS are involved in forums for consultation between representatives of market players and the government such as the MIS in Madagascar (Rice Observatory OdR). Moreover, if they resort to modalities more interactive dissemination (presentations/debates, radio programs or TV with interviews of journalists and calls from the auditors) they can be valuable tools to stimulate the policy debate, especially if their analyses are broadcast not only to decision makers but also to represent professional organizations.

In addition, MIS could also contribute to making policies more predictable by informing operators on the measures that will be implemented in order to reduce the distortions that they are likely to generate on the markets [8]. When it comes to MIS themselves carried by professional organizations, it's up to them to organize the internal discussion within the organization to help her define her position and advocacy. In order to involve as much as possible professional organizations and to allow them to better participate in the debate, complementary 
actions training or strengthening of capabilities can be put in place.

\section{Third Impact: Strengthen the Impact on MIS Equity}

The question is what can the MIS do for poorer? The difficulty for MIS is then to make the information, knowing that the most popular modes of MIS2G (mobile telephony, sites web) are based on technologies which they sometimes do not have access to. Then, the MIS can strengthen the negotiating capacity of the poorest by providing them with information on prices and transaction opportunities. First, it is necessary to emphasize that if MIS make more competitive markets, they can by this means helping the poorest to benefit from best prices, even if these do not receive the MIS information directly.

To strengthen their ability, the first option is working with NGO (Non-Governmental Organizations) helps the MIS financially, also helps them to cover the costs for certain categories of people (such as Esoko MIS did in Ghana) and finally developing USSD platforms that allow users to get a great diversity of information via a simple cell phone, for the cost of one SMS. The second option consists in developing strategies to facilitate access to ICTs (Information and Communication Technology) and reduce costs through awareness-raising and training of users in information available, and how to access. The first is use modes of diffusion inclusive (like local radios) in addition to dissemination tools based on ICT. But the information transmission for an affordable price to illiterate remains difficult because voice systems are more expensive than SMS.

This can be done by formations but also through of educational radio broadcasts (explanations of the dynamics of markets, forecasts, tips, information on the MIS itself or the associated services) or interactive (mini-debates, auditor interventions). In addition to the problem of sending the information to the poorest, another obstacle must be overcome: strengthen their ability to interpret this information and to use them effectively in their production and marketing decisions.

\section{Fourth Impact: Improve the Adjustment Capacity of MIS to the Needs of Users}

This feedback is needed to enable the MIS to constantly, which is to adjust their information offer to the needs actors in the market by proposing regular new types of information and retaining only those who meet a real interest with users. In all the case, this feedback will be useful only if is organized: the information coming from users being collected regularly analyzed and used to adapt the information offer of the MIS. It can also be generated by devices ad hoc (periodic surveys, periodic meetings) with group market players. This feedback can be facilitated by some interactive modes broadcasting by mobile phone, website or radio broadcasts with calls from listeners and certain types of accommodation institutional professional organizations. 


\section{Fifth Impact: The MIS Should Better Take into Account the Constraints of the Market Players}

The MIS carried by professional organizations and NGOs are without a doubt the best placed to provide these services, as illustrated by the case of RATIN (Regional Agricultural Trade Intelligence Network [Kenya]), or in another register, the MIS backed by a commodity exchange like the Ethiopian Commodity Exchange (ECX). This may include credit, storage, and measurement of weight or quantity of the classification quality, agricultural advice, and transport infrastructure. To make information usable by the operators, she often needs to be associated with additional services (regarding the investment in infrastructure), whose nature depends on the constraints facing the actors of the market. Information is certainly necessary but by no means sufficient to improve market efficiency or reduce asymmetries.

\section{Sixth Impact: Good Use of Impacts Studies}

When the evaluation methods can be implemented, the validity of the results obtained is only conditional: the results are valid only in the study context, which is to say in the country studied, on the sample macroeconomic conditions prevailing over the period of study, that do not allow them not to take full advantage of the additional information disseminated by MIS. Although attracting the interest of donors of funds and the subject of an increasing number of studies, microeconomic impact does not allow an evaluation complete of MIS. In addition, low income impacts that we could measure reflects the fact that actors in agricultural markets developing countries already have their own information systems. These methods evaluation are not applicable to all types of MIS, nor to all contexts but also that they face many constraints (credit, transport).

This means that impact assessments should not be used as exclusive criteria to decide whether to continue or not the financing of an MIS. This does not imply that MIS is useless, but rather that make their information really useful supposes to provide services complementary, as indicated previously. It seems much more relevant to use them like a steering instrument allowing MIS better understand the impacts of information they broadcast. Last but not least, current methods of evaluation do not allow us to study the whole potential impacts of MIS. So, MIS often contribute heavily in policy development public, but these impact assessments should not be used as exclusive criteria to decide whether to continue or not the financing of a MIS.

\section{Seventh Impact: Ensuring the Financial Sustainability of MIS}

Faced with this recurrent concern, there are no miracle recipes. Increase the number of users expanding product range and coverage geographical map of the MIS could improve their financial viability while maintaining low access costs. But for being effective, it needs to adapt the particularities of each market, which 
limits the relevance of devices uniforms on a large scale. Recourse (at least partially) to subsidies then seems difficult to avoid. It can be justified by the fact that, as the information contributes to the public decision and to improve fairness, it has a status of public good. Equilibrium is therefore to be found between basic information which must be accessible to all and information more detailed or specific such as market analyzes or individualized advice who can be billed.

The free dissemination of basic information can be supported by public funds while selling more detailed or specific information (e.g. market analysis, quality standards, individual advice) and providing revenue (e.g. brokerage, storage, contracts for the protection of information files between agro-food industries and producers). The need for public funding to make MIS financially viable may be justified by the fact that general market information is a public good. Public-private partnerships can be a way forward for MIS, as this will allow them to use the complementarily of public and private actors.

\section{Conclusions}

Recent research has helped to better know how the MIS works and what its impact on developing countries is. However, some other way can help market transparency like services offered to producers or other market players can also enhance the transparency of markets by another channel. We know in effect that the dissemination of information spontaneously plays by the game of the exchange. The phenomenon is well known by economists (Hayek, 1945; Smith 1982; Kirzner, 1992) and traders (who rely, for example, on to fix their price at the level of affluence on a market place or at the speed of their stocks). These aspects can categorize the MIS as optional for other market actors. As it appears that the quality of this diffusion spontaneous information within marches depends on the institutions which frame the flow of transactions [9], the dissemination of information (by the MIS) is not the only possible action to increase the transparency of markets: it is also possible to act on market institutions to make them more efficient in terms of diffusion of information. And that's what can do some of the services to the actors of the market. For example, setting standards (allowing classifying products in categories of homogeneous quality), warrantage systems (allowing better information on private stocks) or scholarships of goods is of nature to strongly increase transparency steps.

What can lead prices reflect minus less the balance between supplies and request (although information on prices circulates well in the markets, partly thanks to the MIS) because the information aggregated in the prices then becomes very poor. In addition, information distributed by MIS can reinforce practices of collusion (agreement for fixing prices) because it allows control if others respect well the fixed price. Finally, the dissemination of information by the MIS can discourage the efforts made by the actors of the walk to discover or acquire new information. Nevertheless, it would be very useful to develop new research to analyze the process policy development and try to identify the role 
plays by the information from MIS. Regarding the impact of this system on public policies, it cannot be measured because that would imply the policies that would have implemented if decision-makers had not benefited its information which of course is impossible. But it would be without doubt very useful to include them in analyzes, in order to take them into account (to minimize them) to moment of MIS design. Such analyzes would understand if the information has influenced decisions and if so, in what sense and by what channel. They could lead the MIS to modify their practices in order to facilitate the inclusion of information walk in elaboration politics. We can't exaggerate the importance of such effects perverse that does not happen without a doubt that in that in situations enough exceptional. Nevertheless the MIS isn't only challenging their selves by trying to improve over time and make its device effective but also trying to satisfy all the market actors with the organizational innovation including its update (MIS1G to MIS2G).

\section{Conflicts of Interest}

The authors declare no conflicts of interest regarding the publication of this paper.

\section{References}

[1] David-Benz, H., Galtier, F., Subervie, J. and Egg, J. (2014) Agricultural Market Information Systems in Developing Countries: New Models, New Impacts. Cahiers Agricultures, 23, 232-244.

https://www.researchgate.net/publication/275210069_Agricultural_market_informa tion_systems_in_developing_countries_New_models_new_impacts

[2] David-Benz, H., Galtier, F., Egg, J. and Lancon, F. (2012) Market Information Systems. Using MIS Information to Improve Farmers' Market Power and Farmers Organizations' Voice.

https://www.researchgate.net/publication/235897777_Market_information_sytems_U sing_MIS_information_to_improve_farmers'_market_power_and_farmers_organiz ations'_voice

[3] Inter-reseaux (2008) Market Information Systems (MIS): Effective Systems for Better Transparency of Markets.

http://www.inter-reseaux.org/IMG/pdf_SIM_engl.pdf

[4] L'Observatoire du Riz (OdR) http://www.padr.gov.mg/lobservatoire-du-riz-odr/

[5] A Nongovernmental MIS for Vegetables in Madagascar: The SIEL. http://www.sim2g.org/fr/seminaires/atelier_de_montpellier/programme/a_non_gouverneme ntal_mis_for_vegetables_in_madagascar_the_siel_relevance_and_issues_of_the_system_aure lien_penche_institut_des_regions_chaudes

[6] David-Benz, H., Egg, J., Galtier, F., Rakotoson, J., Shen, Y. and Kizito, A. (2012) Les systèmes d'information sur les marchés agricoles en Afrique subsaharienne: De la première à la deuxième génération. AFD, Paris.

http://www.afd.fr/webdav/site/afd/shared/PUBLICATIONS/RECHERCHE/Scientifi ques/Focales/14-Focales.pdf

[7] Rashid, S. and Minot, N.W. (2010) Are Staple Food Markets in Africa Efficient? Spatial Price Analyses and Beyond. 
https://www.researchgate.net/publication/46470919_Are_Staple_Food_Markets_in_ Africa_Efficient_Spatial_Price_Analyses_and_Beyond

[8] De Groote, D.A.H. and Bacha, D. (2006) The Role of the Market Information System in Improving Rural Livelihood and the Status of the Service Ethiopia.

https://repository.cimmyt.org/bitstream/handle/10883/2129/89782.pdf?sequence=1 \&isAllowed $=y$

[9] Egg, J., Dembele, N. and Diarra, S.B. (2014) The Decentralization of Market Information Systems (MIS), an Innovation Designed to Meet Actors' Needs: The Case of the Malian Agricultural Market (OMA). Cahiers Agricultures, 23, 288-294.

https://www.researchgate.net/publication/293062247_The_decentralization_of_mar ket_information_systems_MIS_an_innovation_designed_to_meet_actors'_needs_T he_case_of_the_Malian_agricultural_market_OMA_watch 